International Journal of Biology, Pharmacy and Allied Seiences (IJBPAS) 'A Bridge Betusen Caboratory and Q ander'

WwW.ijbpas.com

\title{
AGE AND GENDER PREDILECTION OF LEUKOPLAKIA IN AN OUTPATIENT POPULATION VISITING A DENTAL COLLEGE
} SINGH AK ${ }^{1}$, S.GHEENA ${ }^{2 *}$ AND DURAISAMY $\mathbf{R}^{3}$

1: Saveetha Dental College and Hospital, Saveetha Institute of Medical and Technical Science, Saveetha University, Chennai-600077, Tamil Nadu, India

2: Department of Oral Pathology, Saveetha Dental College, Saveetha Institute of Medical and Technical Science, Saveetha University, Chennai-600077, Tamil Nadu, India

3: Senior Lecturer, Department of Prosthodontics, Saveetha Dental College, Saveetha Institute Of Medical And Technical Science, Saveetha University, Chennai 07.Tamil Nadu, India

*Corresponding Author: E Mail: Dr. S Gheena:gheena.sdc@saveetha.com Received 19 ${ }^{\text {th }}$ March 2021; Revised 25 ${ }^{\text {th }}$ April. 2021; Accepted 20 ${ }^{\text {th }}$ May 2021; Available online $1^{\text {st }}$ Aug. 2021

https://doi.org/10.31032/IJBPAS/2021/10.8.1077

\section{ABSTRACT}

The aim of the study was to evaluate the age and gender of patients with leukoplakia visiting a Dental College and comparing their age and gender with their habits Oral leukoplakia is potentially malignant disorder affecting the oral mucosa. It is defined as essentially an oral mucosal white lesion that cannot be considered as any other definable lesion. Oral leukoplakia is is a white patch or plaque that develop in the oral cavity and is strongly associated with smoking. Risk factors include alcohol consumption, tobacco use in any form, including cigar, cigarette bedi and pipe. From the data of 86,000 patients who visited the hospital from June 219 to march 2020; data of 317 patients with the diagnosis of leukoplakia were extracted. The report included the age group, gender of patients with their ID and Name. Record of each case were examined and tabulation of the data was done in Excel sheet followed by statistical analysis using SPSS software V 20.0 (IBM). Oral leukoplakia was predominant in the age group (21-30) years. Among male and female gender, leukoplakia was found to be more in males. There was a negative association of age, gender and oral leukoplakia.( $>>0.05)$ chi-square test. This study showed an increased predominance of leukoplakia among males as compared to females and most affected age group range from 21-30 years (younger adult) and statistical association was not significant of (gender*age).

Keywords: Smoking, Tobacco, Gender, oral leukoplakia, oral disease 


\section{INTRODUCTION}

The term leukoplakia was first used in 1877 by Schnuimer to denote any white lesion of the oral cavity [1]. This is the most common precancerous lesion of the oral mucosa. Recently the World Health Organization (WHO) considered premalignant lesions and condition under the terminology of Potentially malignant disorder [2]. Oral leukoplakia is a potentially malignant disorder affecting the oral mucosa, homogeneous type which appears as a flat white lesion and non-.homogeneous type which includes speckled, nodular and verrucous leukoplakia [3]. It is irregular, flat, nodular, or exophytic in nature and resembles mixed red and white non-uniform patches, and has a greater probability of turning into malignancy. The etiology of oral leukoplakia is considered multifactorial, but smoking is appreciated to be a frequently involved factor [4]. It is much more common among smokers than among non-smokers $[\mathbf{5 , 6}$. Proliferative verrucous leukoplakia (PVL) is a distinct clinical form of oral leukoplakia and a rare potentially malignant oral mucosal disorder with a high rate of progression to oral cancer [7].

Alcohol is thought to be an independent risk factor but definitive data are still lacking. There are conflicting results of studies related to the possible role of human papillomavirus infection $[8,9]$. Current developments in oral cancer research have steered to the development and expansion of potentially valuable diagnostic tools at the clinical and micromolecular levels for the timely detection of leukoplakia [10]. The gold standard for diagnosis of leukoplakia is always a biopsy from the site of the lesion [11], but this procedure needs a qualified health-care provider and is considered as an invasive, painful, expensive, and timeconsuming procedure. Identification of biomarkers for oral carcinogenesis is based on markers of proliferation ( $\mathrm{Ki}-67)$ and component of cell cycle control such as tumor suppressor proteins p53, the retinoblastoma protein $(\mathrm{pRb})$ and cyclin $\mathrm{D} 1$ [12]. But none of these markers are used in routine diagnosis. Expression of p53 and loss of expression of p16 are shown to be the earliest events in the maligni process. In nondysplastic leukoplakia a combined alteration of $\mathrm{p} 53 / \mathrm{Ki} 67 / \mathrm{p} 16 \mathrm{INK} 4 \mathrm{a}$ was proven to be a risk of progression [13, 14].

Histopathologically appearance of leukoplakia ranges from hyperkeratosis without epithelial dysplasia to hyperkeratosis with various degrees of epithelial dysplasia $[15,16]$. Its application in diagnosis of 
premalignant lesions is limited due to the occurrence of false negative results, because many lesions have a thick keratinized surface layer and contain subtle changes of dysplasia that may be difficult to detect in a smear [17, 18]. Biopsy is the surgical removal of a tissue from a living person for microscopic examination to confirm or to establish the diagnosis of a disease. It can be excisional biopsy, incisional biopsy or punch biopsy [19]. Excisional biopsy is the total excision of the small lesion (less than $1 \mathrm{~cm}$ in size) for the histopathological examination. Incisional biopsy is the removal of a small, representative portion of the lesion for microscopic examination, if the area under investigation appears difficult to cut the tissue because of its extensive size (i.e. larger than $1 \mathrm{~cm}$ [ $\mathrm{n}$ diameter). Punch biopsy is a form of incisional biopsy in the oral cavity. It is best suited for the diagnosis of mucosal abnormalities that may require multiple biopsies In the case of small lesions, excisional biopsy is indicated, and in large lesions, incisional biopsy, including the adjacent healthy tissue, is removed for histopathological examination. Anywhere from $1 \%$ to $9 \%$ of patients with oral leukoplakia will develop invasive cancer in the lesion or a frank malignancy [20]. Despite the excision of invasive lesions, recurrence is not uncommon. Oral leukoplakia can spontaneously regress, and hence, their outcomes are difficult to follow with treatment [21].

\section{MATERIAL AND METHODS}

\section{Study Setting}

The study setting was basically a university based setting because the available data with similar ethnicity was collected from a particular geographic location. The trends in other locations were not assessed in this study setting. Ethical approval was obtained from the university ethical committee, SDC/SIHEC/2020/DIASDATA/0619-

0320.Case sheet reviewed and cross verification done by external examiners to avoid error. To minimise this sampling bias all available data was included and no sorting process was done. All samples who were diagnosed leukoplakia and their habits at the particular time was considered as internal validity and prescriptive pattern was followed to analyse the eternal validity.

Patient records were reviewed and analysed; the data of 86000 patients between June 2018 to April 2020 was screened to obtain a sample of 317 patients who were diagnosed with Leukoplakia. From the records details of patients initial visit, final visit were collected in a chronological order. These data were entered in excel sheet and tabulated and 
SPSS importing done. Variable were managed by importing to SPSS and defined. Statistical test used was Chi square test and one way anova the software used was SPSS by IBM. Demographic detail such as age, gender of the study participants were recorded. Correlation and association which is a descriptive data analysis is the type of analysis carried out.

\section{RESULTS AND DISCUSSION}

The data for this retrospective study was based on residents of Chennai seeking treatment ata dental hospital. Since all the data was included without any sorting process, no bias was expected in selection of patients. From the results obtained; 317 patients were selected who were of Indian origin in which 301 were male patients and 16 were female patients. In the current study smoking habit was more prevalent in 21-30 year age group (Figure 1). Bokor Bratict et al., 2002 study stated that the age range from 25-34 years had the highest prevalence rate (21\%) [5]. Another study [22] stated that young adults were more prone to smoking habits similar to our results. Some opposing studies like [23] state that the age range 3445 were more affected with this habit. But the overall consensus agreed that the age range from 21-30 years was highly affected with smoking habit which leads to leukoplakia. In Figure 2 shows the correlation between age and gutkha status from where we found that age range of 21-30 years had more gutkha habit followed by age range 31-40 years [24]. Study done by (Sridharan G et al) and (Niaz et al 2017) agreed that the age range from 21-30 years was more prevalent to gutkha habit [25]. On the other hand (Metgud $\mathbf{R}$ et al., .2018) disagree from this study [26], in his study, high prevalence of gutka was found in the age range of $40-50$ years. But the overall consensus agreed that the age range 21-30 years were more prone to gutkha chewing habits. Figure 3 showing the comparison of gender and smoking status. Males are more in number when compared to females. Figure 4 represents the correlation between gender and pan chewing habit we found that males were more affected as compared to females. Pre- existing literature suggests that males are associated more with pan chewing habit than females, which supports the current study [20, 27]. The usage of gutka is increasing for their perceived benefits like mouth freshening, aid in digestion, mood enhancement and tension relief. However, in a study done by Gopinath $\mathrm{D}$, it was stated that there was no significant difference in the prevalence in males and females [22] hence, the overall consensus is that male 
predilection is higher. Figure 5 showing the correlation between gender and gutkha status, we found that male were more addicted to gutkha as compared to females. In a study done by Ali FM et al, stated that males have more prevalence to gutkha habits than females [28]. The possible reason for this maybe that people believe that gutkha is a mouth freshener. Mishra et al. oppose this result, they state that the female were more prevalent as compared to male [29]. But the overall consensus agrees that the male had a higher prevalence of gutkha status as compared to female.

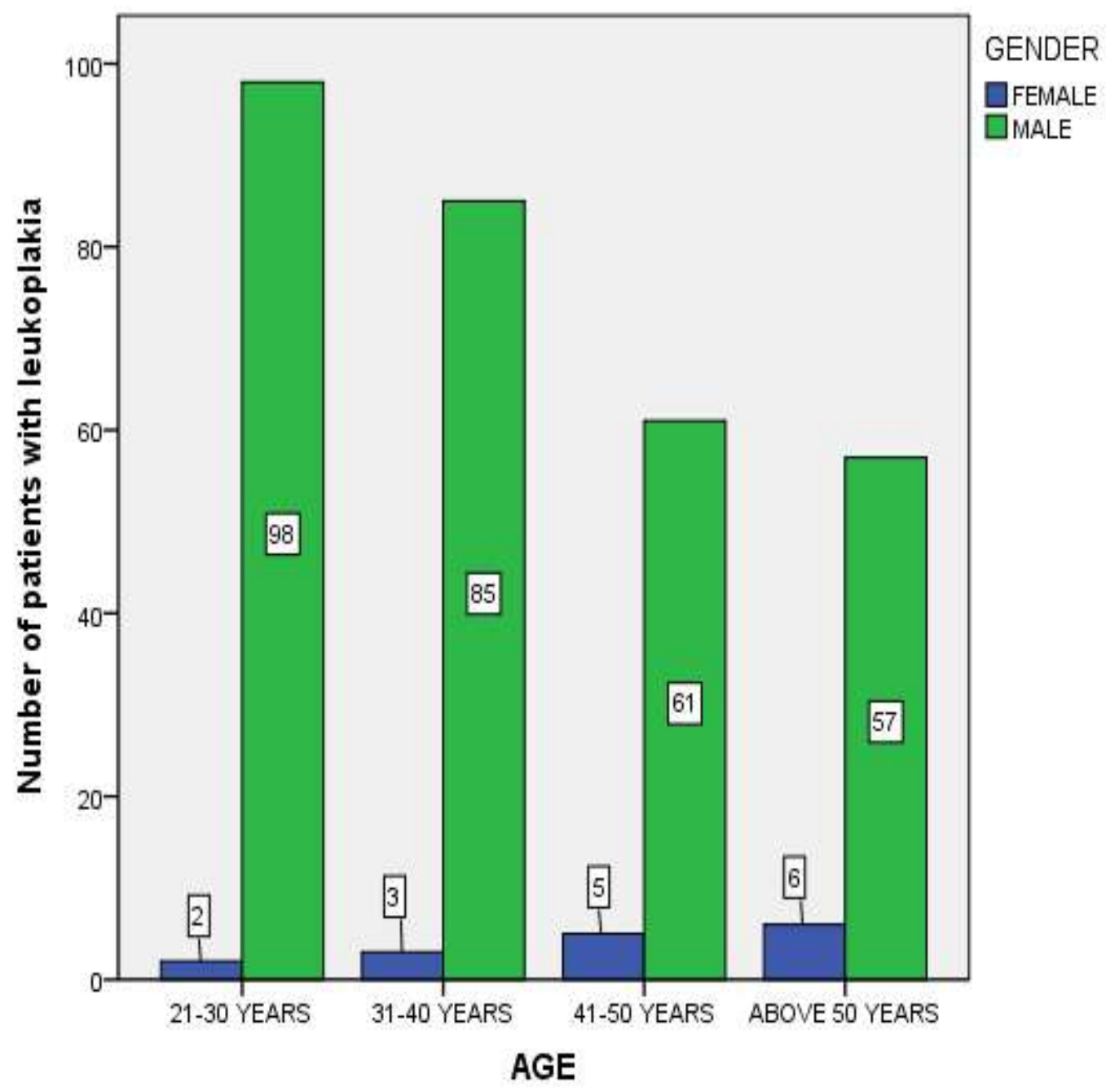

Figure 1: Bar graph representing the association of leukoplakia with age and gender. $X$ axis represents the age $y$ axis represents the number of patients with leukoplakia. Males in the age range from 21-30 years were more prone to leukoplakia followed by 31-40 year olds. Chi square value-5.945 df- 3 p value-0.1 ( $p$ value $>0.05$ ) not significant. Hence there was no major association between gender and the age group affected with leukoplakia. 


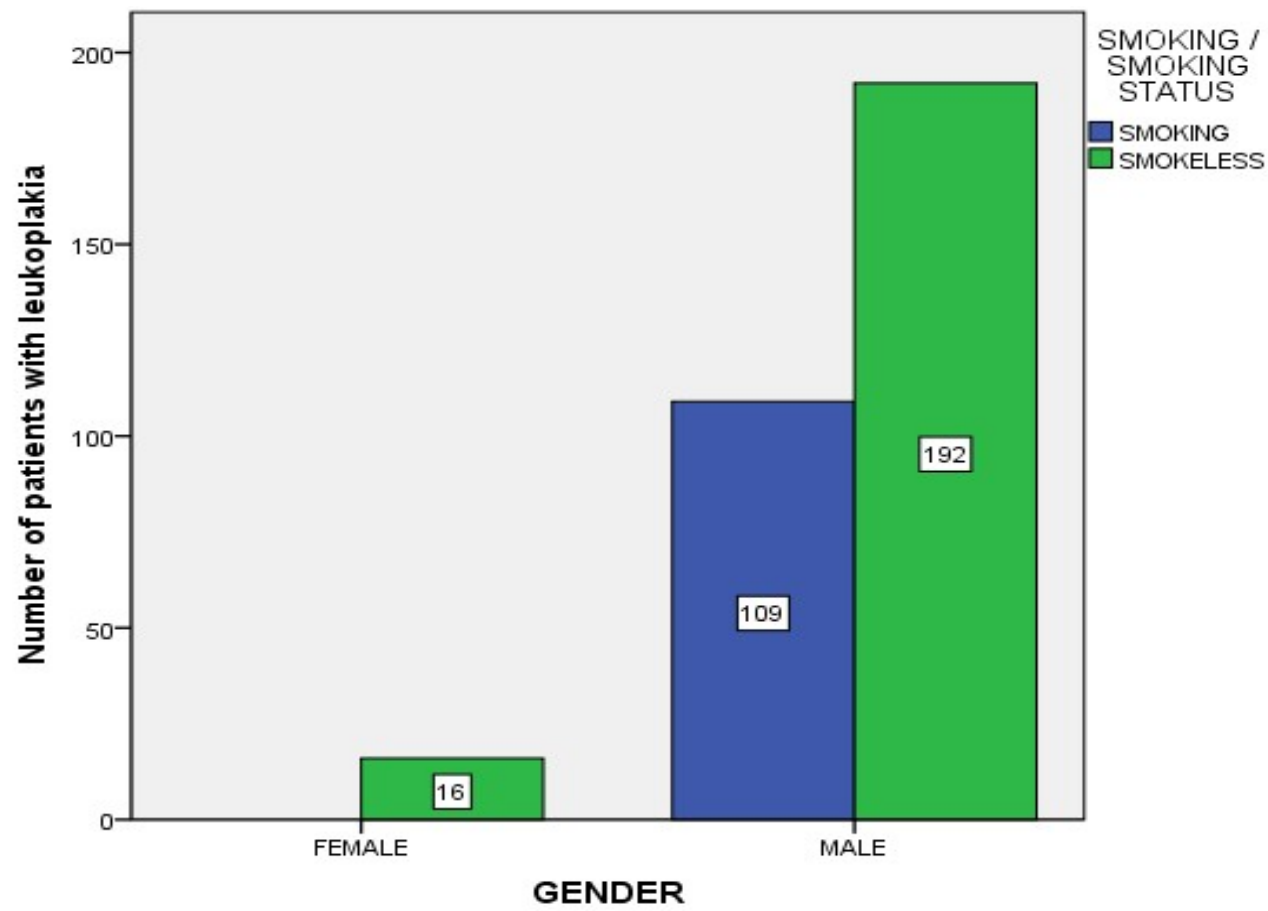

Figure 2 This graph shows the association of gender with oral habit in leukoplakia patients. $X$ axis represents the gender and the $y$ axis represents the number of patients with leukoplakia. smokeless tobacco habit was more among males than the smoking habit. Chi square value- $6.670 \mathrm{df}-1$, p value 0.03 , p value $<0.05$ statistically significant. Hence there is a siginificant association between gender and the oral habit in patients affected with leukoplakia

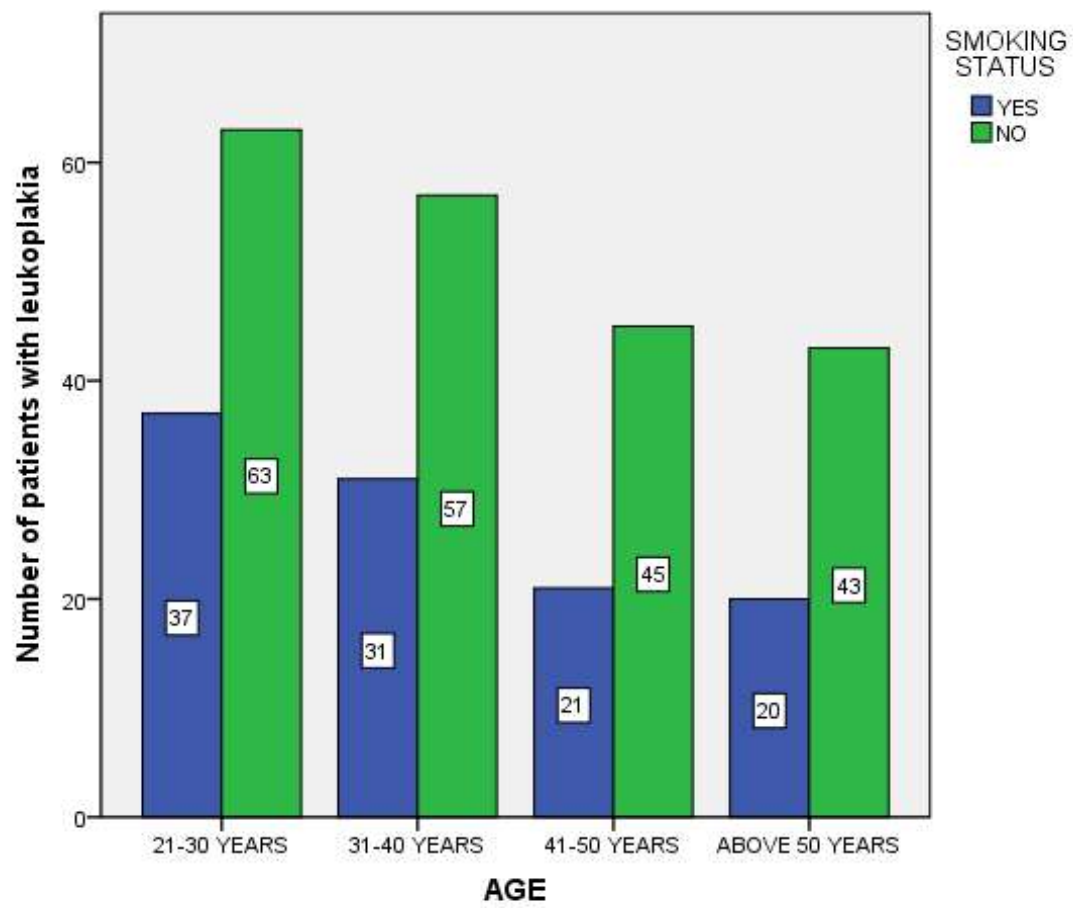

Figure 3: This bar graph showing the association between age and smoking status where age was represented on the $x-$ axis and number of patients with leukoplakia for smoking status was represented on y-axis. Smoking was more common in the age range 21-30 years. Chi square value- $0.718 \mathrm{df}-3 \mathrm{p}$ value- 0.86 ( $\mathrm{p}$ value $>0.05$ ) not significant. Hence there was no statistically significant association between age group and smoking habit. 


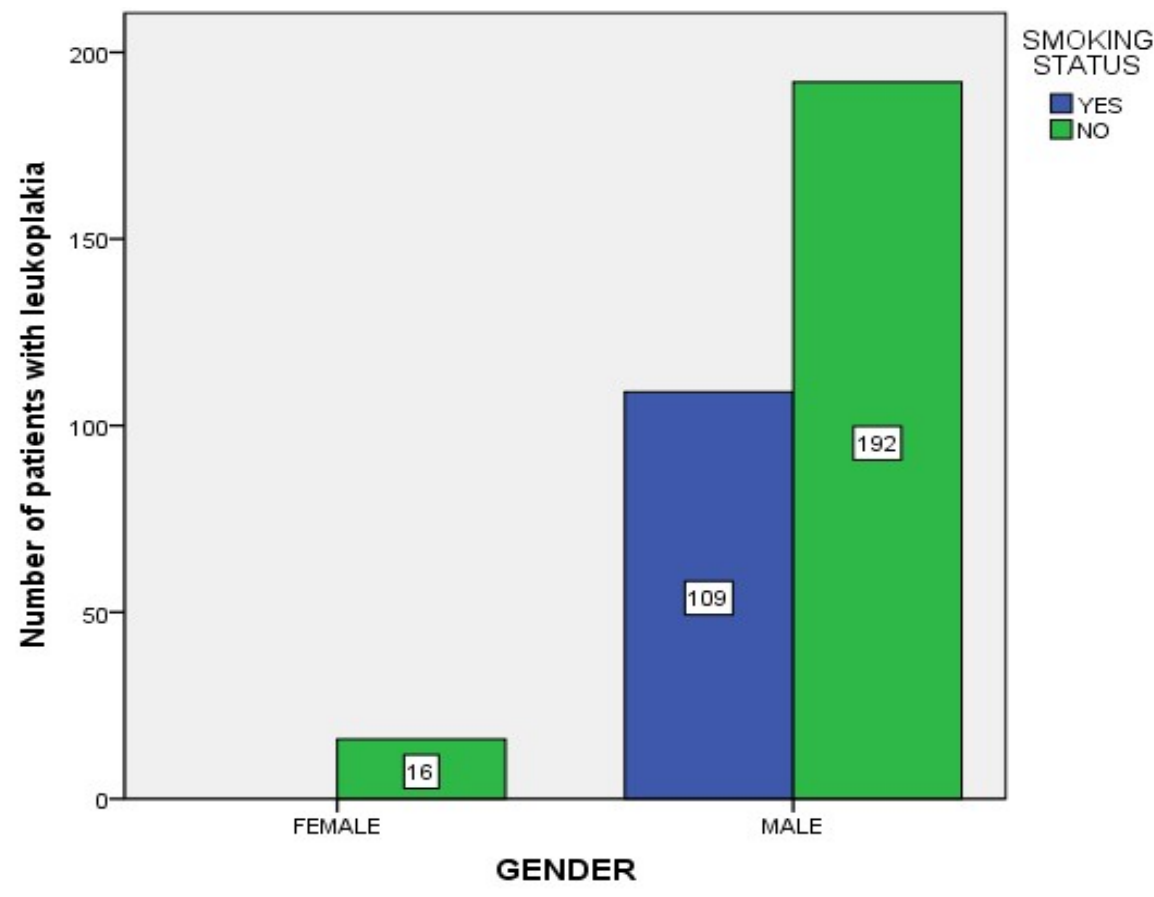

Figure 4: This bar graph shows association between gender and smoking status where gender was represented on $\mathrm{x}$-axis and number of patients with leukoplakia for smoking status was represented on y-axis, (blue) yes and (green) no.Males with smoking habit are more affected with leukoplakia than females. Chi square value-8.830 df-1 p value-0.03, ( $p$ value $<0.05$ ). Hence leukoplakia was more common in males with smoking habit.

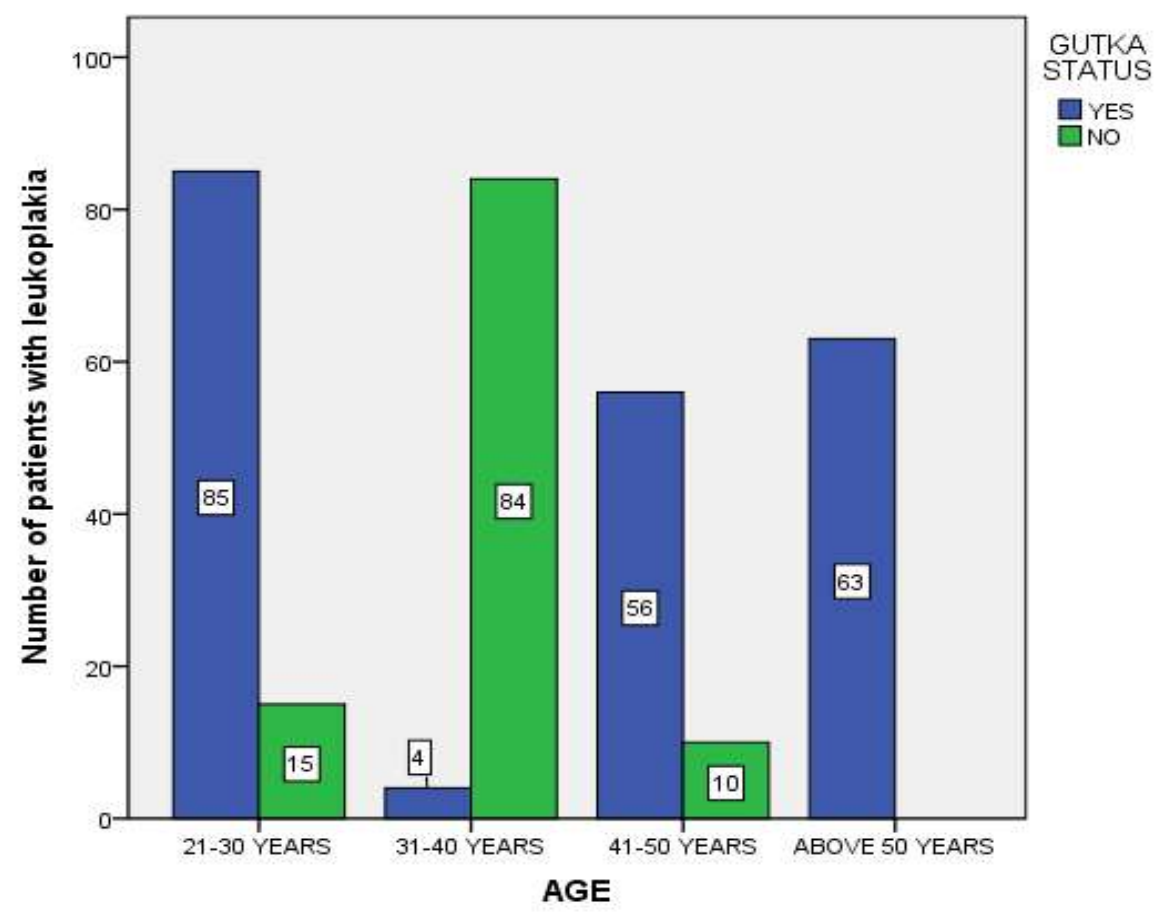

Figure 5: This graph shows the association between age and gutkha status where age was represented on the $x$-axis and number of patients with leukoplakia for gutkha status was represented on $y$-axis where yes (blue), no (green).Gutkha chewing habit was more common in age group of 21-30 years old.Chi square value-5.958 df-3 p value- $0.001(p$ value $<0.05)$ significant. Hence, leukplakia was more common in patients who had a tobacco chewing habit in the age range of 21-30 yrs. 


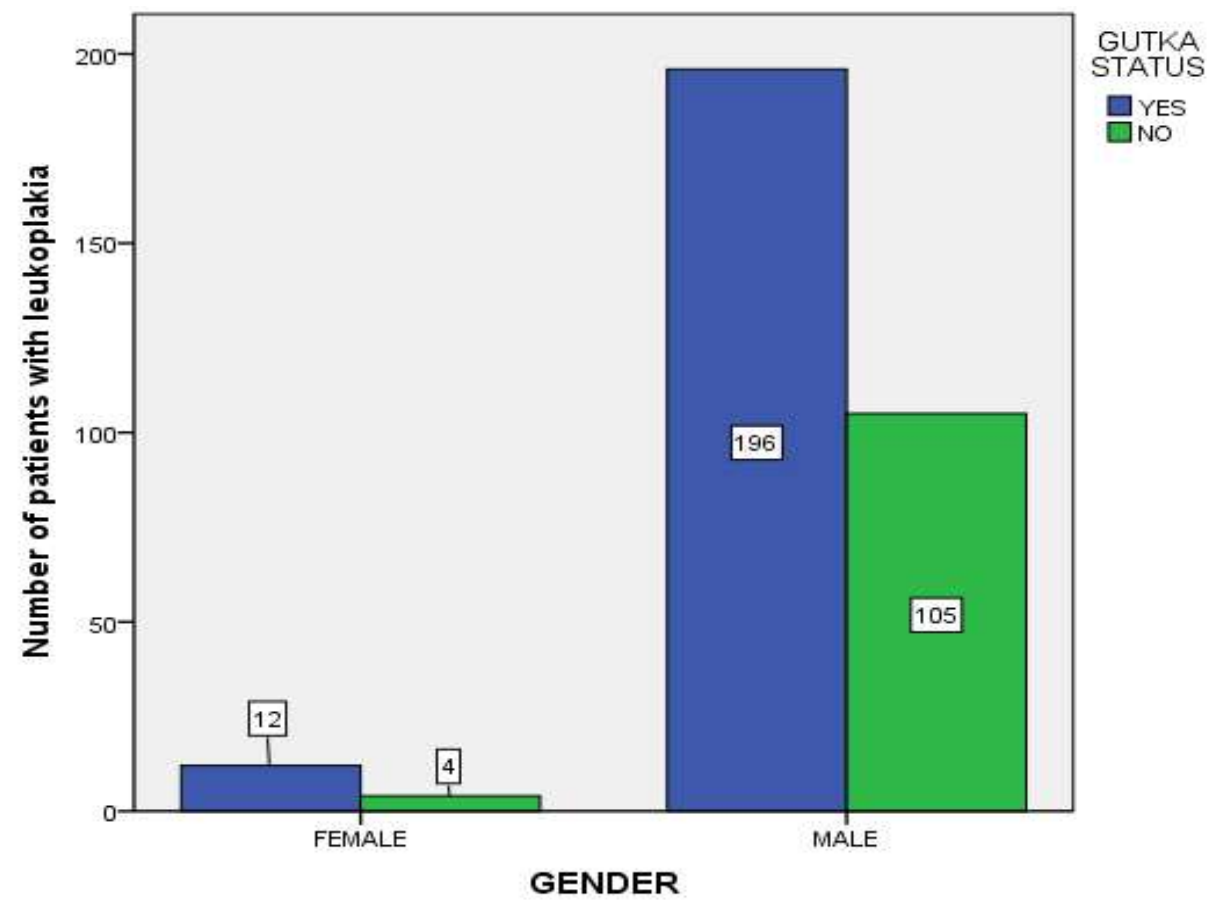

Figure 6: shows the association between gender and gutka status. The association between gender and gutkha habit status where gender was represented on $x$-axis and number of patients with leukoplakia for habit of gutkha status was represented by $\mathbf{y}$-axis. The bar graph depicts that gutkha habit was more prevalent in males compared to females. Chi square value- $0.658 \mathrm{df}-1 \mathrm{p}$ value- 0.4 ( $\mathrm{p}$ value $>0.05$ ). Hence no association between gender and tobacco use was noted.

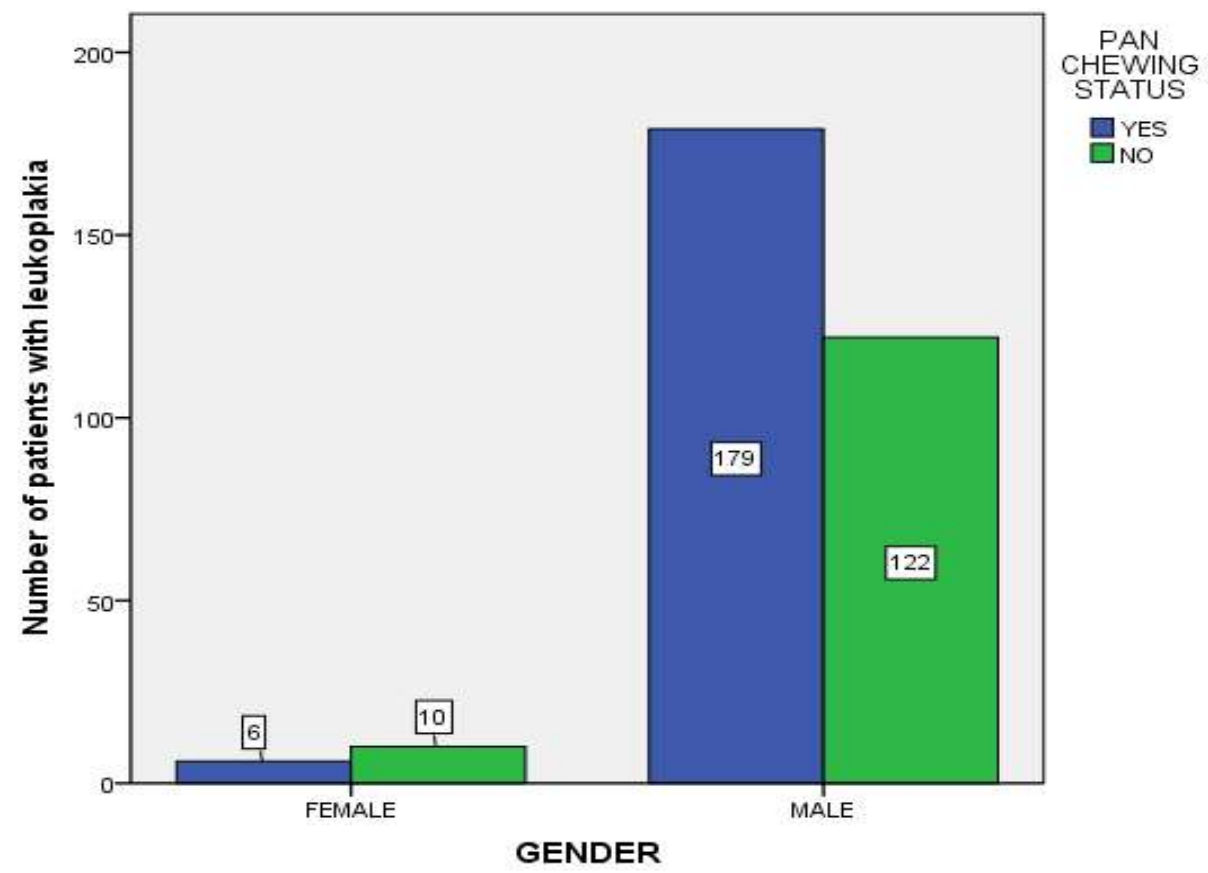

Figure 7 Bar chart shows the association between the gender and paan leaf chewing status, where age was represented on the $x$-axis and number of patients with leukoplakia for pan chewing habit was represented on $y$-axis. Males with paan chewing habit were compared to females.Chi square vale-3.017 $\mathrm{df}-1 \mathrm{p}$ value- 0.8 ( $\mathrm{p}$ value $>0.05$ ). Hence there was no association between gender and paan chewing habit in patients with leukoplakia. 


\section{CONCLUSION}

Our study results revealed a male predominance in the disease population as well as a peak in the 21-30 year age group; the association being statistically significant. There is also an observed association with smoking ,panchewing and gutkha habit which is in concordance with world literature. The association with smoking habit was particularly strong in the study population. This stresses on the importance of cessation of habits to prevent the onset of leukoplakia.

\section{REFERENCES}

[1] Mohammed F, Fairozekhan AT. Oral Leukoplakia. In: StatPearls. Treasure Island (FL): StatPearls Publishing; 2019.

[2] Sridharan G, Ramani P, Patankar S. Serum metabolomics in oral leukoplakia and oral squamous cell carcinoma. J Cancer Res Ther. 2017 Jul;13(3):556-61.

[3] Thangaraj SV, Shyamsundar V, Krishnamurthy A, Ramani P, Ganesan K, Muthuswami M, et al. Molecular Portrait of Oral Tongue Squamous Cell Carcinoma Shown by Integrative Meta-Analysis of Expression Profiles with Validations. PLoS One. 2016 Jun 9;11(6):e0156582.

[4] Swathy S, Gheena S, Varsha SL. Prevalence of pulp stones in patients with history of cardiac diseases. Research Journal of Pharmacy and Technology. 2015;8(12):1625-8.
[5] Bokor-Bratić M, Vučković N. Cigarette smoking as a risk factor associated with oral leukoplakia. Arch Oncol [Internet]. 2002; http://www.doiserbia.nb.rs/Article.aspx?ID= 0354-73100202067B

[6] Warnakulasuriya S, Johnson NW, van der Waal I. Nomenclature and classification of potentially malignant disorders of the oral mucosa. J Oral Pathol Med. 2007 Nov;36(10):575-80.

[7] Sivaramakrishnan SM, Ramani P. Study on the Prevalence of Eruption Status of Third Molars in South Indian Population [Internet]. Vol. 07, Biology and Medicine. $2015 . \quad$ http://dx.doi.org/10.4172/09748369.1000245

[8] Jangid K, Alexander AJ, Jayakumar ND, Varghese S, Ramani P. Ankyloglossia with cleft lip: A rare case report. J Indian Soc Periodontol. 2015 Nov;19(6):690-3.

[9] Jayaraj G, Sherlin H, Ramani P, Premkumar P, Anuja N. Cytomegalovirus and Mucoepidermoid carcinoma: A possible causal relationship? A pilot study [Internet]. Vol. 19, Journal of Oral and Maxillofacial Pathology. 2015. p. 319. Available from: http://dx.doi.org/10.4103/0973-029x.174618

[10] Hannah R, Ramani P, Sherlin HJ, Ranjith G, Ramasubramanian A, Jayaraj G, et al. Awareness about the use, ethics and scope of dental photography among undergraduate dental students dentist behind the lens. Research Journal of Pharmacy and Technology. 2018;11(3):1012-6. 
[11] Lodi G, Porter S. Management of potentially malignant disorders: evidence and critique. $\mathrm{J}$ Oral Pathol Med. 2008 Feb;37(2):63-9.

[12] Nasser W, Flechtenmacher C, Holzinger D, Hofele C, Bosch FX. Aberrant expression of p53, p16INK4a and Ki-67 as basic biomarker for malignant progression of oral leukoplakias. J Oral Pathol Med. 2011 Sep;40(8):629-35.

[13] Viveka TS, Shyamsundar V, Krishnamurthy A, Ramani P, Ramshankar V. p53 expression helps identify high risk oral tongue pre-malignant lesions and correlates with patterns of invasive tumour front and tumour depth in oral tongue squamous cell carcinoma cases. Asian Pac J Cancer Prev. 2016;17(1):189-95.

[14] Gheena S, Ezhilarasan D. Syringic acid triggers reactive oxygen species-mediated cytotoxicity in HepG2 cells. Hum Exp Toxicol. 2019 Jun 1;38(6):694-702.

[15] Jayaraj G, Ramani P, Herald J. Sherlin, Premkumar P, Anuja N. Inter-observer agreement in grading oral epithelial dysplasia - A systematic review [Internet]. Vol. 27, Journal of Oral and Maxillofacial Surgery, Medicine, and Pathology. 2015. p. 112-6. Available from: http://dx.doi.org/10.1016/j.ajoms.2014.01.00 6

[16] Jayaraj G, Sherlin HJ, Ramani P, Premkumar P, Natesan A. Stromal myofibroblasts in oral squamous cell carcinoma and potentially malignant disorders. Indian J Cancer. 2015 Jan;52(1):87-92.

[17] Bánóczy J, Csiba A. Occurrence of epithelial dysplasia in oral leukoplakia. Analysis and follow-up study of 12 cases. Oral Surg Oral Med Oral Pathol. 1976 Dec;42(6):766-74.

[18] Sherlin H, Ramani P, Premkumar P, Kumar A, Natesan A. Expression of CD 68, CD 45 and human leukocyte antigen-DR in central and peripheral giant cell granuloma, giant cell tumor of long bones, and tuberculous granuloma: An immunohistochemical study [Internet]. Vol. 26, Indian Journal of Dental Research. 2015. p. 295. Available from: http://dx.doi.org/10.4103/0970-9290.162872

[19] Gupta V, Ramani P. Histologic and immunohistochemical evaluation of mirror image biopsies in oral squamous cell carcinoma. J Oral Biol Craniofac Res. 2016 Sep;6(3):194-7.

[20] Saraswathi TR, Ranganathan K, Shanmugam S, Sowmya R, Narasimhan PD, Gunaseelan R. Prevalence of oral lesions in relation to habits: Cross-sectional study in South India. Indian J Dent Res. 2006 Jul;17(3):121-5.

[21] Parlatescu I, Gheorghe C, Coculescu E, Tovaru S. Oral leukoplakia - an update. Maedica . 2014 Mar;9(1):88-93.

[22] Gopinath D, Thannikunnath BV, Neermunda SF. Prevalence of Carcinomatous Foci in Oral Leukoplakia: A Clinicopathologic Study of 546 Indian 
Samples. J Clin Diagn Res. 2016 Aug;10(8):ZC78-83.

[23] Lee J-M. The synergistic effect of cigarette taxes on the consumption of cigarettes, alcohol and betel nuts. BMC Public Health. 2007 Jun 25;7:121.

[24] Sridharan G, Ramani P, Patankar S, Vijayaraghavan R. Evaluation of salivary metabolomics in oral leukoplakia and oral squamous cell carcinoma. J Oral Pathol Med. 2019 Apr;48(4):299-306.

[25] Niaz K, Maqbool F, Khan F, Bahadar H, Hassan FI, Abdollahi M. Smokeless tobacco (paan and gutkha) consumption, prevalence, and contribution to oral cancer [Internet]. Vol. 39, Epidemiology and Health. 2017. p. e2017009. Available from: http://dx.doi.org/10.4178/epih.e2017009

[26] Metgud R, Murugesh CJ, Shiva Kumar BN, Priya NK, Rashmi P, Naik $S$, et al. Prevalence, knowledge, and attitude of gutkha chewing among school children of Arsikere, India. J Cancer Res Ther. 2018 Jan;14(2):368-71.

[27] Rooban T, Joshua E, Rao U, Ranganathan K. Prevalence of chewable smokeless tobacco in Indian women: Secondary data analysis from national family health survey 2005-06 [Internet]. Vol. 2, Journal of Dr. NTR University of Health Sciences. 2013. p. $29 . \quad$ Available from: http://dx.doi.org/10.4103/2277-8632.108510 [28] Ali FM, Aher V, Prasant MC, Bhushan P, Mudhol A, Suryavanshi H. Oral submucous fibrosis: Comparing clinical grading with duration and frequency of habit among areca nut and its products chewers. J Cancer Res Ther. 2013 Jul;9(3):471-6.

[29] Mishra GA, Kulkarni SV, Gupta SD, Shastri SS. Smokeless tobacco use in Urban Indian women: Prevalence and predictors. Indian J Med Paediatr Oncol. 2015 Jul;36(3):176-82. 